\title{
Plasma cholinesterase deficiency in a neonate: $a$ follow-up
}

To the Editor:

We reported a two-day-old infant in 1993 who had apnoea lasting six hours following the intravenous administration of succinylcholine. ${ }^{\prime}$ The results of the plasma cholinesterase level and dibucaine number indicated a congenital absence of plasma cholinesterase enzyme. Her cholinesterase activity measured at three days of age was $0.2 \mathrm{U} \cdot \mathrm{ml}^{-1}$ (normal: 3.4-6.5 $\mathrm{U} \cdot \mathrm{ml}^{-1}$ ) and the dibucaine number was $<5 \%$ (normal 73-90\%). Both parents and siblings had normal cholinesterase levels and dibucaine numbers, and it was felt that the parents were heterozygous for the silent gene.

In a Letter to the Editor, Drs. Vassallo and Goudsouzian suggested that analysis of plasma cholinesterase activity should be made at an older age in our patient before a definitive diagnosis of cholinesterase deficency is made. ${ }^{2}$

At 27 mo, our patient returned for a follow-up plasma cholinesterase level which was $0.2 \mathrm{U} \cdot \mathrm{ml}^{-1}$. The dibucaine number could not be calculated due to the low value for plasma cholinesterase. This confirms that our patient does have cholinesterase deficiency and not a transiently low level of plasma cholinesterase activity due to her young age.

Caroline A. Pasquariello MD

Roy E. Schwartz MD

St. Christopher's Hospital for Children

Philadelphia, Pa.

\section{REFERENCES}

1 Pasquariello CA, Schwartz RE. Plasma cholinesterase deficiency in a neonate. Can J Anaesth 1993; 40: 529-31.

2 Vassallo SA, Goudsouzian NG. Plasma cholinesterase activity in infants (Letter). Can J Anaesth 1994; 41: 654.

\section{$R E P L Y$}

It is reassuring to learn that Drs. Pasquariello and Schwartz were able to obtain a follow-up plasma cholinesterase level when the above patient reached 27 months of age. Repeat testing confirmed a very low plasma cholinesterase activity and now a definitive diagnosis of cholinesterase deficiency is appropriate. We applaud their persistence.

Susan A. Vassallo MD

Nishan G. Goudsouzian MD

Departments of Anesthesia

Massachusetts General Hospital/

Harvard Medical School

Boston 